\title{
Stature estimation for personal identification using mandibular morphometric parameters in Italian population: a preliminary report
}

\author{
Chantal Milani, Rolando Milani, Gian Luigi Panattoni \\ Department of Neurosciences, University of Torino, Italy
}

\begin{abstract}
Stature is fundamental in personal identification for forensic and physical anthropologists. When a full skeleton is not available, stature can be estimated from incomplete human remains. It is also important to apply a method to estimate the stature based on the same specific population of the remains. For this purpose, we measured 4 distances between cephalometric landmarks of the mandible and the stature in 56 subjects (both males and females) from Caucasian Italian population. The correlation between these parameters appeared to be statistically significant, so that it was possible to establish a regression equation to estimate the stature from the mandible in this population.
\end{abstract}

\section{Introduction}

Forensic and physical anthropologists can estimate the stature of an individual from fragmented or incomplete human remains. ${ }^{1-5}$ In literature, anatomical methods based on measurements of the whole skeleton or mathematical methods based on measurements of single bones have been developed in order to obtain regression formulae for calculating the stature. Since abnormal development of the mandible is involved in growth disorders, ${ }^{6-8}$ we investigated possible correlations between some mandibular morphometric parameters and stature in normal subjects of an Italian population in relation to personal identification in anthropologic or forensic practice.

Correspondence: Gian Luigi Panattoni, Department of Neurosciences, University of Torino, corso Massimo D'Azeglio 52, 10124 Torino, Italy. Tel.+39.011.6636327 - Fax:+39.011.6963487.

E-mail: gianluigi.panattoni@unito.it

Key words: forensic anthropology, mandible, stature estimation.

Aknowledgments: we thank Prof. G.C. Isaia and Dr. M. Di Stefano, Department of Medical Sciences, Geriatrics Section, University of Torino, and Col. G. Beraldo and Ten. Col. L. Giai from the Scuola di Applicazione dell'Esercito Italiano, Torino, Italy, for their kind support to our study.

(C) Copyright C. Milani et al., 2014

Licensee PAGEPress, Italy

Journal of Biological Research 2014; 87:2130

doi:10.4081/jbr.2014.2130

This article is distributed under the terms of the Creative Commons Attribution Noncommercial License (by-nc 3.0) which permits any noncommercial use, distribution, and reproduction in any medium, provided the original author(s) and source are credited.

\section{Materials and Methods}

Measures were acquired in 56 individuals of both sexes ( 36 males ranging from 20 to 66 years old, 20 females ranging from 20 to 65 years old) from Caucasian Italian population (born in Italy and with Italian parents). Stature and distances between the following cephalometric landmarks of both mandibular sides were measured: Co-Co (bicondylar distance); Go-Go (bigonial distance); Co-Go (condylion-gonion distance); Go-Gn (gonion-gnathion distance) (Figure 1). The stature of the subjects was measured in standing position to the vertex by using a non-stretch, retractable anthropometric tape. The mandibular parameters were measured by a digital anthropometric head caliper. The mandible dimension (MD) was also considered as the sum of the co-go-gn distances of both sides. The possible statistical relationships between MD and the measured living stature (MLS) were investigated by Pearson correlation analysis ( $\mathrm{r}$ coefficient) in order to obtain the estimated living stature (ELS).

\section{Results}

Mean age and MLS of the specimens are reported in Table 1. In the whole sample, ELS is expressed by the multivariate linear regression formula:

$\mathrm{ELS}=(-759) \mathrm{Co}-\mathrm{co}+(2.260) \mathrm{Go}-\mathrm{Go}+(5.946) \mathrm{Co}-\mathrm{Go}+(6.691) \mathrm{Go}-\mathrm{Gn}+73.442$ $\mathrm{R}^{2}=0.502 ; \mathrm{r}=0.708 ; \mathrm{SE}=7.427$

The linear regression formula obtained from MD is:

$\mathrm{ELS}=(3.1843) \mathrm{MD}+74.299$

$\mathrm{R}^{2}=0.4761 ; \mathrm{r}=0.690 ; \mathrm{SE}=7.399 ; \mathrm{P}<0.05$

The similar values of $r$ and $R^{2}$ of these two formulae suggest that MD may be considered as a reliable parameter for stature estimation (Figure 2).

ELS regression formulae based on the single distances is showed in Table 2. $\mathrm{R}^{2}, \mathrm{r}$ and standard error (SE) shows that Go-Gn distance is the most reliable $(\mathrm{P}<0.05)$ (Figure 3$)$.

\section{Discussion}

As the estimated living stature obtained by mathematical method is population-specific, in this preliminary report we examined in particular a sample of Caucasian Italian population. We chose the sum of bilateral Co-Go-Gn distances as a reference dimension of the mandible because these values seem to be the most significant for representing 


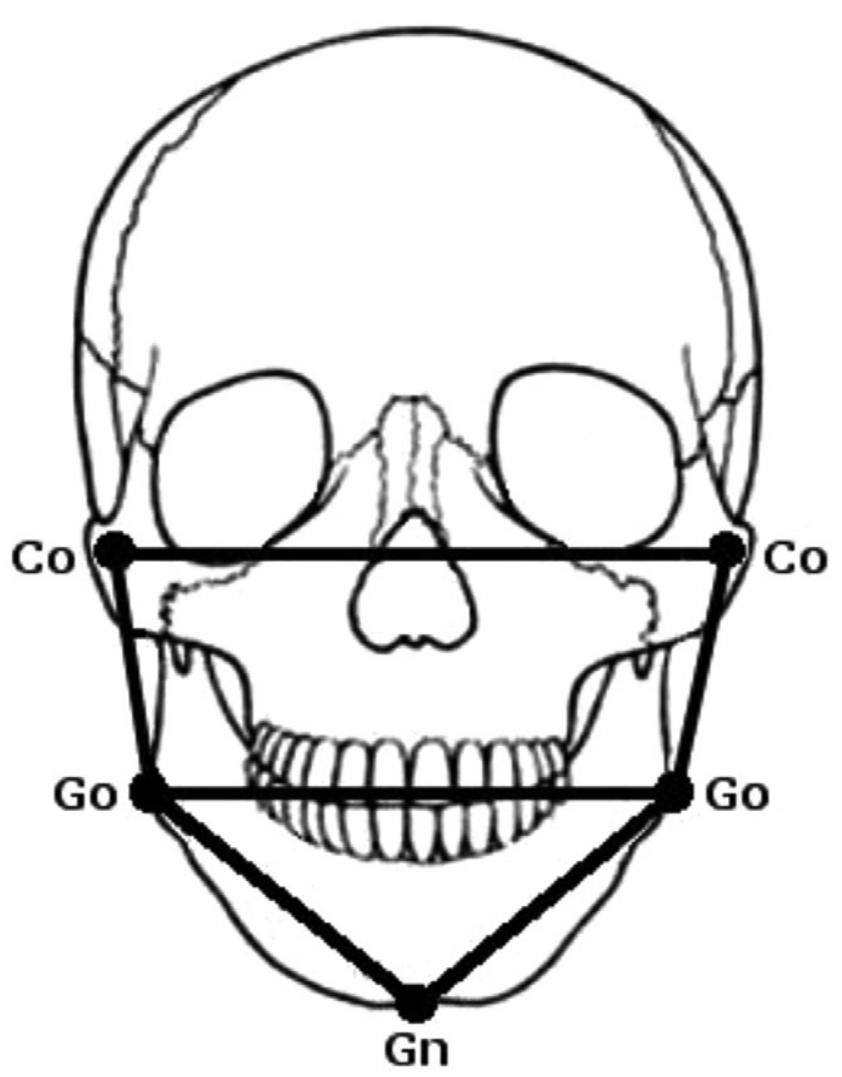

Figure 1. Landmarks and distances used for the measurements.

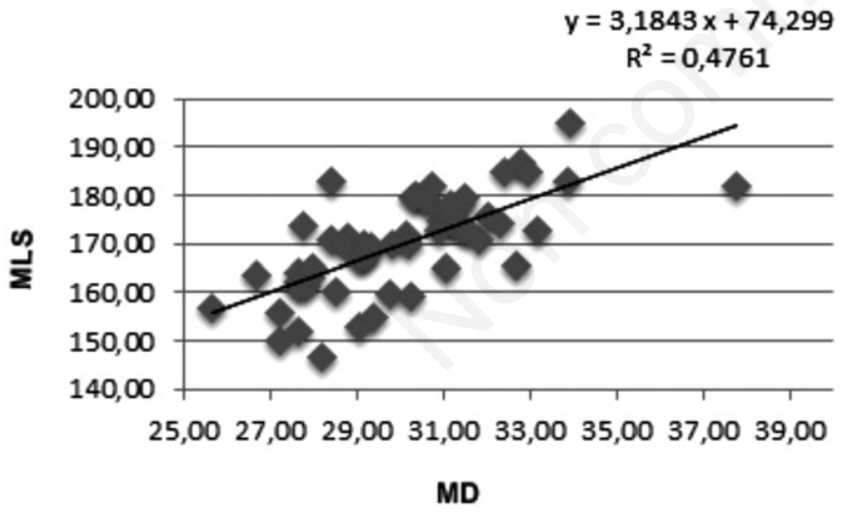

Figure 2. Correlation between the sum of bilateral Co-Go-Gn (MD) and the measured living stature (MLS).

Table 1. Mean age and measured living stature of the observed specimens.

\begin{tabular}{lcc} 
& Mean age (years) & Mean MILS (cm) \\
Males & 33.9 & 175.8 \\
Females & 40.4 & 159.9 \\
\hline
\end{tabular}

MLS, measured living stature.

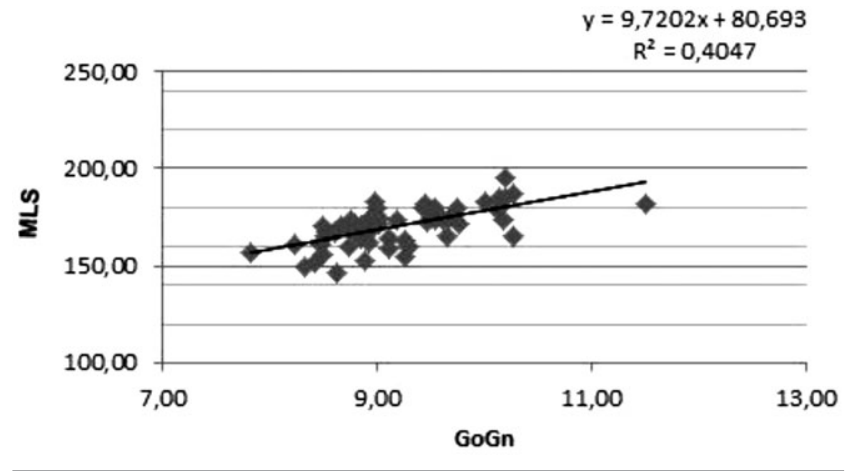

Figure 3. Correlation between Go-Gn distance and measured living stature (MLS).

Table 2. Estimated living stature regression formulae based on the single distances.

\begin{tabular}{lllll}
$\begin{array}{l}\text { Mandibular } \\
\text { distances }\end{array}$ & \multicolumn{1}{c}{ Equation } & $\mathrm{R}^{2}$ & $\mathrm{r}$ & $\mathrm{SE}$ \\
Co-Co & $\mathrm{ELS}=(5.0636) \mathrm{CoC}+105.17$ & 0.139 & 0.373 & 9.490 \\
Go-Go & $\mathrm{ELS}=(7.076) \mathrm{GoGo}+98.332$ & 0.232 & 0.482 & 8.959 \\
\hline Co-Go & $\mathrm{ELS}=(8.650) \mathrm{CoG}+119.57$ & 0.287 & 0.536 & 8.635 \\
Go-Gn & $\mathrm{ELS}=(9.720) \mathrm{GoGn}+80.693$ & 0.405 & 0.636 & 7.888 \\
\hline
\end{tabular}

$\mathrm{SE}$, standard error; $\mathrm{Co}-\mathrm{Co}$, bicondylar distance; ELS, estimated living stature; Go-Go, bigonial distance; Co-Go, condylion-gonion distance; Go-gn, gonion-gnathion distance.

mandibular growth. In fact, the mandible grows with a progressive posterior increase in length of the body and in height of the rami. In literature, some researches ${ }^{9-11}$ show a very low correlation between mandibular morphometry and stature, while in other works ${ }^{12}$ the correlation is moderate like the one showed by our data; these differences could be due to the various factors that affect the mandibular growth (e.g. orthodontic treatments).

\section{References}

1. Fully G, Pineau H. [Détermination de la stature au moyen du squelette]. [Article in French]. Ann Méd Lég 1960;40:145-54.

2. Raxter MH, Auerbach BM, Ruff CB. Revision of the fully technique for estimating statures. Am J Phys Anthropol 2006;130:374-84.

3. Krogman WM, can MY. Calculation of stature. In: Krogman WM, can MY, eds. Human skeleton in forensic medicine. Charles C. Thomas ed.: Springfield, IL, USA;1986. pp 302-51.

4. Trotter M, Gleser G. A re-evaluation of estimation of stature based on measurements of stature taken during life and of long bones after death. Am J Phys Anthropol 1958;16:79-123.

5. Wilson RJ, Herrmann NP, Jantz LM. Evaluation of stature estimation from the database for forensic anthropology. J Forensic Sci 2010;55:684-9.

6. Takakura M, Kuroda T. Morphologic analysis of dentofacial structure in patients with acromegaly. Int J Adult Orthodon Orthognath Surg 1998;13:277-88.

7. Dostálová S, Sonka K, Amahel Z, et al. Cephalometric assessment 
of cranial abnormalities in patients with acromegaly. J Craniomaxillofac Surg 2003;31:80-7.

8. Kjellberg H, Wikland KA. A longitudinal study of craniofacial growth in idiopathic short stature and growth hormone-deficient boys treated with growth hormone. Eur J Orthodont 2007;29:243-50.

9. Agnihotri AK, Kachhwaha S, Googoolye K, Allock A. Estimation of stature from cephalo-facial dimensions by regression analysis in Indo-Mauritian population. J Forensic Leg Med 2011;18:167-72.
10. Pelin C, Za yapan R, Yazici C, Kürkçüo lu A. Body height estimation from head and face dimensions: a different method. J Forensic Sci 2010;55:1326-30.

11. Sahni D, Sanjeev, Sharma P, et al. Estimation of stature from facial measurements in northwest Indians. Leg Med (Tokyo) 2010;12:23-7.

12. Kalia S, Shetty SK, Patil K, Mahima VG. Stature estimation using odontometry and skull anthropometry. Indian J Dent Res 2008;19:150-4. 